\title{
Hexamethylenetetramine as an Efficient Catalyst for One-Pot, Three Component Synthesis of 2-Amino-4H-Pyran Derivatives
}

\author{
S Y. BEHESHTIHA*, H A. OSKOOIE, F S. POUREBRAHIMI and V. ZADSIRJAN \\ Department of Chemistry, School of Sciences, Alzahra University, Vanak, Tehran, Iran \\ syshirazi@yahoo.com
}

Received 15 November 2014 / Accepted 28 November 2014

\begin{abstract}
Hexamethylenetetramine has been found to be an efficient catalyst for the preparation of 2 -amino- $4 H$-pyran derivatives in ethanol. The products were obtained with very good yields.
\end{abstract}

Keywords: Hexamethylenetetramine, 2-Amino-4H-pyran, Dimedone, Multicomponent reaction

\section{Introduction}

Tetrahydrobenzo [b] pyrans have shown a broad spectrum of biological and pharmacological activities ${ }^{1}$, such as anticancer, antianaphylactin, anticoagulant and diuretic characteristics $^{2-4}$. These compounds have been of interest to the medicinal chemist for many years. They have been used as cognitive enhancers for the treatment of neurodegenerative diseases, including Huntington's disease, Alzheimer's disease, amyotrophic lateral sclerosis, AIDS-associated dementia, and Down's syndrome, as well as for the treatment of schizophrenia and myoclonus ${ }^{5}$, additionally; these compounds are used as photoactive materials ${ }^{6}$ and occur in a variety of natural products ${ }^{7}$. Because of their applications, the syntheses of heterocyclic derivatives of these compounds have attracted a great deal of attention in medicinal chemistry. One-pot multi-component condensations represent as possible instrument to perform a near ideal synthesis because they possess one of the aforementioned qualities, namely the possibility of building-up complex molecules with maximum simplicity and brevity ${ }^{8}$.

2-Amino-4H-pyrans are generally prepared by the condensation of dimedone with aromatic aldehydes and malononitrile under refluxing in DMF or acetic acid ${ }^{9,10}$ or the bicomponent condensation of dimedone with $\alpha$-cyanocinnamonitriles in the presence of ethanolic piperidine ${ }^{11}$.

In recent years, hexadecyldimethyl benzyl ammonium bromide ${ }^{12}$, triethylbenzylammonium chloride $^{13}$, rare earth perfluorooctanoate ${ }^{14},(S)$-proline ${ }^{15}$, the use of microwave irradiation ${ }^{16}$, KF-basic alumina under ultrasound irradiation ${ }^{17}$ and amino- functionalized ionic 
liquid $^{18}$, Caro's acid-silica gel ${ }^{19}, 1,4-D i a z a b i c y c l o[2.2 .2]$ octane $(\mathrm{DABCO})^{20}, \mathrm{Ce}\left(\mathrm{SO}_{4}\right)_{2} \cdot 4 \mathrm{H}_{2} \mathrm{O}^{21}$, cerium(III) chloride ${ }^{22}$ and $\mathrm{ZnO}$-beta $\mathrm{Zeolite}^{23}$ have been reported to catalyze these reactions. However, in these methods are very useful but many of these methods are associated with several drawbacks such as applications of expensive reagents, low yields, drastic reaction conditions, the use of harmful organic solvents, high temperatures, extended reaction times, occurrence of side products, unsatisfactory yields and complicated experimental procedure. Hence, there is a need to develop a convenient, efficient and practically useful process for the synthesis of 2-amino- $4 H$-pyrans.

Hexamethylenetetramine is a heterocyclic organic compound with the formula $\left(\mathrm{CH}_{2}\right)_{6} \mathrm{~N}_{4}$. This white crystalline compound is highly soluble in water and polar organic solvents. It has a cage-like structure similar to adamantane. Hexamethylenetetramine has received significant attention as a powerful catalyst for effecting various organic transformations ${ }^{24-27}$.

In our continued interest in the development of highly expedient methods for the synthesis of heterocyclic compounds ${ }^{28-31}$, we wish to introduce hexamethylenetetramine as a mild and highly efficient catalyst for the preparation of 2-amino- $4 H$-pyrans under room temperature condition (Scheme 1).<smiles>[R]CC1([R])CC(=O)CC(=O)C1</smiles>

\section{Expermental}

ints were 9200 apparatus. ${ }^{1} \mathrm{H}$ NMR spectra were recorded on a Bruker AQS AVANCE-500 MHz spectrometer using TMS as an internal standard $\left(\mathrm{CDCl}_{3}\right.$ solution). IR spectra were recorded from $\mathrm{KBr}$ disk on the FT-IR Bruker Tensor 27. GC/Mass analysis was performed using Agilent $6890 \mathrm{GC}$ system Hp-5 capillary $30 \mathrm{~m} \times 530 \mu \mathrm{m} \times 1.5 \mu \mathrm{m}$ nominal. All products were characterized by spectra and physical data.

\section{Preparation of 2-amino-4H-pyrans: General procedure}

A mixture of benzaldehyde $(1 \mathrm{mmol})$, malononitrile $(1 \mathrm{mmol})$ and an $\alpha$-methylencarbonyl compound $(1 \mathrm{mmol})$ in the presence of hexamethylenetetramine $(0.03 \mathrm{~g})$ was taken in a round-bottomed flask in ethanol $(5 \mathrm{~mL})$ and stirred at room temperature for appropriate time as indicated in Table 4. After completion of the reaction which was monitored by TLC, the mixture was obtained was filtered off and washed with $\mathrm{H}_{2} \mathrm{O}$. The crude products were purified by recrystallization from $\mathrm{EtOH}$.

\section{Results and Discussion}

At first, the synthesis of 2-amino- $4 H$-pyran was investigated through condensation dimedone, benzaldehyde and malononitrile in the presence of catalytic amount of hexamethylenetetramine, for optimization of the reaction conditions. The reaction of dimedone $(1 \mathrm{mmol})$, benzaldehyde $(1 \mathrm{mmol})$ with malononitrile $(1 \mathrm{mmol})$ in different solvents and the absence of solvent under room temperature in the presence of a catalytic amount of hexamethylenetetramine was studied (Scheme 1). The results are summarized in Table 1. Ethanol was found to be a good solvent for this reaction. 
Table 1. Synthesis of 2-amino- $4 H$-pyran in different conditions in the presence of hexamethylenetetramine

\begin{tabular}{cccc}
\hline Entry & Temperature & Time, min & Yield, ${ }^{a}{ }^{\mathrm{a}}$ \\
\hline 1 & Room temperature & 35 & 92 \\
2 & Reflux & 25 & 65 \\
\hline \multicolumn{4}{c}{}
\end{tabular}

${ }^{a}$ Yields refer to isolated products

Next, we studied the effect of different amounts of catalyst in the condensation of dimedone $(1 \mathrm{mmol})$, benzaldehyde $(1 \mathrm{mmol})$ with malononitrile $(1 \mathrm{mmol})$. The results are summarized in Table 2.

We investigated above reaction in different temperatures in order to define the best condition. The results are summarized in Table 3.

Table 2. Synthesis of 2-amino- $4 H$-pyran in different solvents in the presence of hexamethylenetetramine

\begin{tabular}{cccc}
\hline Entry & Solvent & Time min & Yield, $\%^{\mathrm{a}}$ \\
\hline 1 & No solvent & 60 & 45 \\
2 & Water & 150 & 80 \\
3 & Ethanol & 35 & 92 \\
4 & Acetonitrile & 120 & 55 \\
\hline
\end{tabular}

${ }^{a}$ Yields refer to isolated products

Table 3. Synthesis of 2-amino- $4 H$-pyran in the presence of different amounts of hexamethylenetetramine

\begin{tabular}{cccc}
\hline Entry & Catalyst & Time, min & Yield, $\%^{\mathrm{a}}$ \\
\hline 1 & 0.01 & 60 & 86 \\
2 & 0.02 & 90 & 89 \\
3 & 0.03 & 35 & 92 \\
\hline \multicolumn{4}{c}{ Yields refer to isolated products }
\end{tabular}

The optimized methodology was applied to the synthesis of a variety of 2-amino- $4 \mathrm{H}$ pyran derivatives. Hexamethylenetetramine as an efficient medium for this reaction affords the product in excellent yield. Using this optimized condition, we examined threecomponent condensation of various aldehydes with active $\alpha$-methylencarbonyl compounds and malononitrile. The results are summarized in Table 4. The results clearly indicate the scope of the reaction with respect to different substrates. It is noteworthy to mention that, the effect of the nature of the substituents on the aromatic ring showed no obvious effect on this conversion, because they were obtained in high yields in relatively short reaction times. All compounds were known and their physical data were compared with those of authentic compounds and found to be identical.

Table 4. Hexamethylenetetramine catalyzed synthesis of 2-amino-4H-pyran derivatives.

\begin{tabular}{ccccccc}
\hline \multirow{2}{*}{ Entry } & $\begin{array}{c}\text { Active methylene } \\
\text { compound }\end{array}$ & $\mathrm{Ar}$ & $\begin{array}{c}\text { Time, } \\
\text { min }\end{array}$ & $\begin{array}{c}\text { Yield, } \\
\%{ }^{\mathrm{a}}\end{array}$ & \multicolumn{2}{c}{ Found,${ }^{\circ} \mathrm{C}$} \\
& dimedone & $\mathrm{C}_{6} \mathrm{H}_{5}$ & 90 & 91 & 230 & $228-230[32]$ \\
1 & dimedone & $4-\mathrm{NO}_{2}-\mathrm{C}_{6} \mathrm{H}_{4}$ & 35 & 92 & 179 & $179-180[32]$ \\
2 & dimedone & $3-\mathrm{NO}_{2}-\mathrm{C}_{6} \mathrm{H}_{4}$ & 60 & 90 & 212 & $208-211[32]$ \\
3 & & & & & & Contd
\end{tabular}




\begin{tabular}{ccccccc}
\hline 4 & dimedone & $4-\mathrm{Cl}-\mathrm{C}_{6} \mathrm{H}_{4}$ & 30 & 88 & 216 & $215-216[32]$ \\
5 & dimedone & $4-\mathrm{MeO}-\mathrm{C}_{6} \mathrm{H}_{4}$ & 100 & 81 & 204 & $201-202[32]$ \\
6 & dimedone & $4-\mathrm{Me}-\mathrm{C}_{6} \mathrm{H}_{4}$ & 105 & 87 & 224 & $223-225[32]$ \\
7 & dimedone & $3-\mathrm{MeO}-\mathrm{C}_{6} \mathrm{H}_{4}$ & 60 & 70 & 188 & $186-187[21]$ \\
8 & dimedone & $2-\mathrm{MeO}-\mathrm{C}_{6} \mathrm{H}_{4}$ & 20 & 90 & 198 & $195-197[20]$ \\
9 & dimedone & $3-\mathrm{Br}_{-} \mathrm{C}_{6} \mathrm{H}_{4}$ & 30 & 75 & 292 & $293-294[21]$ \\
10 & 1,3 -cyclohexanedione & $\mathrm{C}_{6} \mathrm{H}_{5}$ & 30 & 93 & 240 & $239-241[32]$ \\
11 & 1,3 -cyclohexanedione & $4-\mathrm{NO}_{2}-\mathrm{C}_{6} \mathrm{H}_{4}$ & 30 & 95 & 237 & $234-236[32]$ \\
12 & 1,3 -cyclohexanedione & $3-\mathrm{NO}_{2}-\mathrm{C}_{6} \mathrm{H}_{4}$ & 60 & 93 & 201 & $198-200[32]$ \\
13 & 1,3 -cyclohexanedione & $4-\mathrm{Cl}-\mathrm{C}_{6} \mathrm{H}_{4}$ & 90 & 91 & 229 & $226-229[32]$ \\
14 & 1,3 -cyclohexanedione & $4-\mathrm{MeO}-\mathrm{C}_{6} \mathrm{H}_{4}$ & 60 & 81 & 198 & $195-197[32]$ \\
15 & 1,3 -cyclohexanedione & $4-\mathrm{Me}-\mathrm{C}_{6} \mathrm{H}_{4}$ & 90 & 94 & 226 & $223-225[32]$ \\
\hline
\end{tabular}

${ }^{a}$ Yields refer to isolated products

\section{Conclusion}

In conclusion, we have demonstrated a highly efficient procedure for the preparation of 2-amino- $4 H$-pyrans through the multi-component reaction of aldehydes, $\alpha$-methylencarbonyl compounds and malononitrile in the presence of hexamethylenetetramine. This simple procedure is an efficient methodology that has advantages such as short reaction times, easy work up, high yields of products, mild condition as well as simple experiment and isolation procedures which makes it very useful and attractive process for the synthesis of these biology active compounds.

\section{Acknowledgment}

S.Y. Beheshtiha acknowledged for the partial financial support from Alzahra University.

\section{References}

1. Green G R, Evans J M and Vong A K, In Comprehensive Heterocyclic Chemistry II, Vol. 5, Eds., Katrizky A R, Rees C W and Scriven E F V, Pergamon, New York, $1995,469$.

2. Andreani L L and Lapi E, Bull Chim Farm., 1960, 99, 583-586.

3. L. Bonsignore, G. Loy, D. Secci, A. Calignano, Eur J Med Chem., 1993, 28(6), $517-$ 520; DOI:10.1016/0223-5234(93)90020-F

4. Konkoy C S, Fick D B, Cai S X, Lan N C and Keana J F W, PCT Int. Appl. WO. 2000, 00,75,123; Chem Abstr., 2000, 134, 29313 a.

5. Arnesto D, Horspool W M, Martin N, Ramos A and Seaone C, J Org Chem., 1989, 54(13), 3069-3072; DOI:10.1021/jo00274a021

6. Hatakeyama S, Ochi N, Numata H and Takano S, J Chem Soc., Chem Commun., 1988, 1202-1204; DOI:10.1039/C39880001202

7. Hudlicky T, Chem Rev., 1996, 96(1), 3-30; DOI:10.1021/cr950012g

8. Armesto D, Horspool W M, Martin N, Ramos A and Seaone C, J Org Chem., 1989, 54(13), 3069-3072; DOI:10.1021/jo00274a021

9. Kamaljit S, Jasbir S and Harjit S, Tetrahedron, 1996, 52(45), 14273-14280; DOI:10.1016/0040-4020(96)00879-4

10. Wang X S, Shi D Q, Tu S T and Yao C S, Synth Commun., 2003, 33(1), 119-126; DOI:10.1081/SCC-120015567 
11. Hassanien A A, Zahrran M A, El-Gaby M S A, Ghorab M M, Hassanien A A, Zahran M A, El-Gaby M S A and Ghorab M M, J Indian Chem Soc., 1999, 76, 350.

12. Jin T S, Wang A Q, Shi F, Han L S, Liu L B and Li T S, Arkivoc, 2006, xiv, 78-86.

13. Shi D Q, Zhang S, Zhuang Q Y, Tu S J and Hu H W, Chin J Org Chem., 2003, 23, 877-879.

14. Wang L M, Shao J H, Tian H, Wang Y H and Liu B, J Fluorine Chem., 2006, 127(1), 97-100; DOI:10.1016/j.jfluchem.2005.10.004

15. Balalaie S, Bararjanian M, Amani A M and Movassagh B, Synlett, 2006, 263-266; DOI:10.1055/s-2006-926227

16. Tu S J, Gao Y, Guo C, Shi D and Lu Z, Synth Commun., 2002, 32(14), 2137-2141; DOI:10.1081/SCC-120005420

17. Li J T, Xu W Z, Yang L C and Li T S, Synth Commun., 2004, 34(23), 4565-4571; DOI:10.1081/SCC-200043233

18. Penjg $\mathrm{Y}$ and Song G, Catal Commun., 2007, 8(2), 111-114; DOI:10.1016/j.catcom.2006.05.031

19. Oskooie H A, Heravi M M, Karimi N and Ebrahim Zadeh M, Synth Commun., 2011, 41(3), 436-440; DOI:10.1080/00397911003587499

20. Tahmassebi D, Bryson J A and Binz S I, Synth Commun., 2011, 41(18), 2701-2711; DOI:10.1080/00397911.2010.515345

21. Islami M R and Mosaddegh E, Phosphorus Sulfur, Silicon, 2009, 184(12), 31343138; DOI:10.1080/10426500802704969

22. Sabitha G, Arundhathi K, Sudhakar K, Sastry B S and Yadav J S, Synth Commun., 2009, 39(3), 433-442; DOI:10.1080/00397910802378399

23. Katkar S S, Lande M K, Arbad B R and Gaikwad S T, Chin J Chem., 2011, 29(1), 199-202; DOI:10.1002/cjoc.201190052

24. Zhao S H, Bie H Y and Chen Zh B, Org Prep Proced Int., 2005, 37(3), 231-237; DOI:10.1080/00304940509354952

25. Santra P K, Kishore D and Jain P, Synth Commun., 2003, 33(21), 3695-3706; DOI:10.1081/SCC-120025178

26. Lapina M, Pevzner L M and Potekhin A A, Russ J Gen Chem., 2006, 76(8), 1304 1309; DOI:10.1134/S1070363206080251

27. Cao Ch, Lu Z, Cai Z, Pang G and Shi Y, Synth Commun., 2012, 42(2), 279-284; DOI:10.1080/00397911.2010.523857

28. Heravi M M, Rahimzadeh M, Bakavoli M and Ghassemzadeh M, Tetrahedron Lett., 2004, 45(29), 5747-5749; DOI:10.1016/j.tetlet.2004.05.094

29. Heravi M M, Rahimzadeh M, Bakavoli M and Ghassemzadeh M, Tetrahedron Lett., 2005, 46(10), 1607-1610; DOI:10.1016/j.tetlet.2005.01.091

30. Heravi M M, Tajbakhsh M, Ahmadi A N and Mohajerani B, Monatsh Chem., 2006, 137(2), 175-179; DOI:10.1007/s00706-005-0407-7

31. Heravi M M, Bakhtiari K, Tehrani M H, Javadi N M and Oskooie H A, Arkivoc, 2006, xvi, 16-22.

32. Sun W B, Zhang P, Fan J, Chen Sh H and Zhang Z H, Synth Commun., 2010, 40(3), 587-594; DOI:10.1080/00397910903007079 